\title{
Mathematical Models of Cross Protection in the Epidemiology of Plant-Virus Diseases
}

\author{
X.-S. Zhang and J. Holt
}

Natural Resources Institute, University of Greenwich, Central Avenue, Chatham Maritime, Kent, ME4 4TB, UK. Current address of X.-S. Zhang: Institute of Cell, Animal and Population Biology, University of Edinburgh, Edinburgh EH9 3JT, UK. Accepted for publication 6 June 2001.

\begin{abstract}
Zhang, X.-S., and Holt, J. 2001. Mathematical models of cross protection in the epidemiology of plant-virus diseases. Phytopathology 91:924-934.

Mathematical models of plant-virus disease epidemics were developed where cross protection occurs between viruses or virus strains. Such cross protection can occur both naturally and through artificial intervention. Examples of diseases with continuous and discontinuous crop-host availability were considered: citrus tristeza and barley yellow dwarf, respectively. Analyses showed that, in a single host population without artificial intervention, the two categories of host plants, infected with a protecting virus alone and infected with a challenging virus, could not coexist in the long term. For disease systems with continuous host availability, the virus (strain) with the higher basic reproductive number $\left(R_{0}\right)$ always excluded the other eventually; whereas, for discontinuous systems, $R_{0}$ is undefined and the virus (strain) with the larger natural transmission rate was the one that persisted in the model formulation. With a proportion of hosts artificially inoculated with a protecting mild
\end{abstract}

ABSTRACT

Cross protection, first shown by McKinney (41) with Tobacco mosaic virus (TMV), is a phenomenon whereby prior infection with one (protecting) plant virus will prevent or interfere with superinfection by another, usually related (challenging) virus. In this article, "virus" refers to either virus or virus strain. The two viruses can replicate and spread independently in isolation but, in the presence of the protecting virus, the host plant becomes resistant to superinfection with the challenging virus, or symptoms of the challenging virus are suppressed. Some examples of cross protection are shown in Table 1 . The phenomenon has economically important applications in agriculture $(17,19,34,67)$. In order to control some virulent virus diseases, it may be possible to develop or select an avirulent or mild protecting virus. Success in virus control by cross protection depends on whether the avirulent virus can invade and replace the virulent virus, and whether reestablishment of the virulent virus is prevented. "Invasion" of mild viruses usually involves artificial inoculation as many have very low transmission rates by vectors under natural conditions.

Cross protection occurs with viruses of perennial and annual crops and in tropical and temperate climates. In considering the epidemiology of diseases in such systems, we also consider the effect of crop-host continuity. In tropical or perennial systems, crop-hosts are more likely to be available throughout the year than in temperate or annual systems, where crop-host availability may be discontinuous. Thus, two different types of pathosystem can be recognized. Disease systems with continuous crop-host availability include those where the host is available throughout the year,

Corresponding author: J. Holt; E-mail address: j.holt@gre.ac.uk

Publication no. P-2001-0725-02R

(C) 2001 The American Phytopathological Society virus, the disease caused by a virulent virus could be depressed or eliminated, depending on the proportion. Artificial inoculation may be constant or adjusted in response to changes in disease incidence. The importance of maintaining a constant level of managed cross protection even when the disease incidence dropped was illustrated. Investigations of both pathosystem types showed the same qualitative result: that managed cross protection need not be $100 \%$ to eliminate the virulent virus (strain). In the process of replacement of one virus (strain) by another over time, the strongest competition occurred when the incidence of both viruses or virus strains was similar. Discontinuous crop-host availability provided a greater opportunity for viruses or virus strains to replace each other than did the more stable continuous cropping system. The process by which one Barley yellow dwarf virus replaced another in New York State was illustrated.

Additional keywords: annual crops, disease control, exclusion, perennial crops, vector. such as woody perennials and some annuals in tropical agroecosystems (e.g., lowland rice) $(27,28,69)$. Disease systems with discontinuous crop-host availability include annuals in temperate climates. Temporal breaks in the crop sequence can impose rigorous barriers to the continuity of a virus disease (30). Viruses and vectors must survive on other hosts during the off season, and wild and cultivated grasses and crop volunteers may play an important role. Perennial hosts can act as reservoirs for primary virus spread into an annual crop (26). Although some degree of host seasonality and ecological disturbance is ubiquitous, this topic has received little attention in theoretical studies of plant-pathogen systems $(22,23,27,28,64)$.

Citrus tristeza (CT) and barley yellow dwarf (BYD) disease are examined in detail as examples of systems with continuous and discontinuous crop-host availability, respectively. CT is caused by an aphid-transmitted virus, Citrus tristeza virus (CTV), that is widespread in citrus-growing areas and has caused great commercial losses (7). This virus has numerous strains that differ in their biological properties, some of which cause mild symptoms and others severe symptoms. Mild strains occur commonly in the field (21), and they are transmissible by grafting and by aphids. Some of them protect infected plants against the effects of virulent strains in tests with aphids and grafts. Plants that had been cross protected with selected mild strains grew well, had slight symptoms of tristeza, and produced good yields compared with plants from the same clones that either had not been cross protected or had been inoculated with severe isolates (45). CTV provides an example of one of the most successful uses of cross protection (17).

CTV is transmitted by several aphid species in a semipersistent manner (54). The most efficient vector species is Toxoptera citricida; Aphis gossypii is the next most efficient (55). Marked differences in the transmission of CTV strains have been observed 
(e.g., for two strains which were related, a virulent one had a significantly higher transmission rate [approximately eightfold] by the aphid A. gossypii than a mild one) (6). To simplify the analysis presented here, we suppose that there are two strains, one causing severe symptoms and the other mild, and that cross protection is conferred through prior infection with the mild strain. Transmission is assumed to occur naturally by vectors and, for the protecting mild strain, also by artificial inoculation.

BYD is the most widespread and economically important virus disease of small grain cereals (49). Five different Barley yellow dwarf viruses (BYDVs) are recognized and named, according to their principal aphid vectors, PAV, MAV, RPV, RMV, and SGV (Tables 1 and 2). They can be divided into different genera according to serological relatedness $(39,44)$ (Table 2). Among these five viruses, different interactions have been observed: synergism, where mixed infection with BYDVs from different genera (e.g., PAV and RPV) give more severe symptoms than do infections with either virus alone (43); helper-dependency between RPV and MAV in aphid Rhopalosiphum padi transmission (57); and cross protection between MAV and PAV (61). We focus on the interaction between MAV and PAV, which is also of particular economic importance. The interaction between MAV and PAV can take place within the vector Sitobion avenae and within the host plant (53). Fewer aphids transmitted PAV if they had first acquired MAV (20) but not vice versa (61); once established within a host plant, each virus conferred resistance to invasion by the other $(1,31,65)$. Field data collected during a 10-year study (1967 to 1976) showed that the mixtures of PAV and MAV were very rare (58-60). It has been suggested that a variety of factors (production of winged aphid morphs, vector preference behavior, vector movement, and vector abundance) favor the transmission of PAV rather than MAV (53). In New York State, a gradual change occurred in the predominant virus from MAV to PAV in the 20 years from 1957 to 1976 (58) and, two decades later, there was no indication that the dominance of PAV had changed (42).

Although much attention has been given to mathematical modeling of interactions between animal and human viruses (3, $11,33,36,37,47)$, there is little theoretical work on interactions between plant viruses $(14,69)$. The mathematical models of interactions between animal and human viruses make theoretical predictions about the evolution of virulence. The models that do not include superinfection $(11,33,37)$ lead to a "competitive exclusion principle" that the virus with the highest basic reproductive number will outcompete the other. The models that include superinfection $(3,36,47)$ demonstrate that evolution is driven by a tradeoff between the benefits of high transmission and the concomitant costs of increased virulence. Whether coexistence or exclusion occurs is determined by the parameters of the virus and the demographic characteristics of the hosts.

In this study, we construct mathematical models to investigate the epidemiology of plant-virus diseases that involve cross protection between viruses. A mathematical model for a disease system with continuous crop-host availability was devised to explore epidemic outcomes under different management strategies. Within this model, two different strategies of artificial inoculation were considered and their effectiveness for disease control was investigated. A second mathematical model incorporating discontinuous crop-host availability was devised that offered a possible explanation for the historic change in the predominant BYDV in New York State (58).

\section{THEORY AND APPROACH}

Let us first consider the general case of complete, unilateral cross protection between two viruses (i.e., infection by the mild virus precludes completely that by the virulent one, but not vice versa). For simplicity, only infection of the host was modeled. We suppose the protecting virus is less virulent than the challenging virus, and describe them as "mild" and "virulent," respectively. There are four categories of host plants: healthy, infected with the mild virus alone, infected with the virulent virus alone, and infected with both, designated as $X, Y, Z$, and $U$, respectively. Assuming that, following infection, the host plant does not recover, there are seven possible sequences of transmission among the four categories (Table 3). The usual bilinear infection rates were employed (i.e., the rate of infection was equal to a product of the number of healthy plants, the number of infected plants, and a transmission rate).

Virus infection may cause host damage and death. Host plant losses due to infection may take the form of actual plant mortality

TABLE 2. Viruses and major vectors of Barley yellow dwarf viruses (Family: Luteoviridae) $^{\mathrm{a}}$

\begin{tabular}{lllc}
\hline Virus & Genus $^{\mathrm{b}}$ & \multicolumn{1}{c}{ Major vector } & Virulence \\
\hline PAV & Luteovirus & $\begin{array}{l}\text { Sitobion avenae } \\
\text { Rhopalosiphum padi } \\
\text { Schizaphis graminum }\end{array}$ & Most severe \\
MAV & Luteovirus & $\begin{array}{l}\text { Sitobion avenae } \\
\text { Schizaphis graminum }\end{array}$ & Moderately severe \\
SGV & $*$ & Rhopalosiphum maidisi & Mild \\
RMV & $*$ & Rhopalosiphum padi & Mild \\
RPV & Polerovirus & & \\
\hline
\end{tabular}

${ }^{a}$ References: 39, 44, 56, and 58.

$\mathrm{b} *=$ Species unassigned within the family (39).

TABLE 1. Examples of cross protection between plant viruses ${ }^{\mathrm{a}}$

\begin{tabular}{|c|c|c|c|c|}
\hline Host plant & Protecting virus ${ }^{\mathrm{b}}$ & Challenging virus & Transmission & Sources \\
\hline Tobacco (annual) & Green mosaic strain of TMV (tobamovirus*) & Yellow mosaic strain of TMV & Mechanical & $(13,41)$ \\
\hline Tobacco (annual) & Mild strain of Potato virus $X$ (potexvirus*) & Severe strain of Potato virus $X$ & Mechanical & (63) \\
\hline Tomato (annual) & Very mild strain of PSTVd (Viroids) & Severe strains of PSTVd & Mechanical & (10) \\
\hline $\begin{array}{l}\text { Cereal (barley, wheat, } \\
\text { and oats) (annual) }\end{array}$ & MAV, a BYDV (luteovirus: luteoviridae) & PAV, a BYDV & $\begin{array}{l}\text { Persistent by Sitobion avenae, } \\
\text { Rhopalosiphum padi }\end{array}$ & $(53,61)$ \\
\hline Cacao (perennial) & $\begin{array}{l}\text { Mild strain of CSSV } \\
\text { (badnavirus: caulimoviridae) }\end{array}$ & Severe strains of CSSV & $\begin{array}{l}\text { Semipersistent by mealybugs: } \\
\text { Planococcoides njalensis, others }\end{array}$ & $(51)$ \\
\hline Zucchini (annual) & $\begin{array}{l}\text { ZYMV-WK of ZYMV } \\
\text { (potyvirus: potyviridae) }\end{array}$ & Severe strains of ZYMV & $\begin{array}{l}\text { Nonpersistent by Myzus persicae, } \\
\text { A. gossypi, others }\end{array}$ & (34) \\
\hline Papaya (perennial) & $\begin{array}{l}\text { Mild mutant PRV strain (PRV HA 5-1) of } \\
\text { PRSV (potyvirus: potyviridae) }\end{array}$ & Severe strains of PRSV & Nonpersistent by Myzus persicae & (67) \\
\hline
\end{tabular}

$\overline{\mathrm{a}} \mathrm{TMV}=$ Tobacco mosaic virus, $\mathrm{PSTVd}=$ Potato spindle tuber viroid, BYDV = Barley yellow dwarf virus, CSSV = Cacao swollen-shoot virus, CTV $=$ Citrus tristeza virus, $\mathrm{ZYMV}=$ Zucchini yellow mosaic virus, and $\mathrm{PRSV}=$ Papaya ringspot virus .

$\mathrm{b} *=$ Family unassigned (40). 
or simply the presence of reduced amounts of host biomass due to reduced growth of diseased plants. Net reduction due to infection is given by $m Y, n Z$, and $w U$, where $m, n$, and $w$ are the loss rates associated with infection by protecting virus alone, infection by challenging virus alone, and mixed infection (per day), respectively. The parameters $m, n$, and $w$ also could be regarded as roguing rates, which were conducted according to the symptoms. The rate of host natural mortality is denoted by $\beta$.

It was assumed that there was a maximum plant population $K$ and, to replace losses, new planting took place at a net rate $f$. A proportion, $q$, of new planting material was artificially inoculated by the protecting mild virus. On these assumptions, a general mathematical model of the infection dynamics of plant disease incorporating managed cross protection is depicted in the flow chart of Figure 1A and is specified by equations 1 .

$$
\begin{aligned}
& d X / d t=(1-q) f-p_{1} X Y-p_{2} X Z-p_{3} X U-p_{4} X U-p_{5} X U-\beta X \\
& d Y / d t=q f+p_{1} X Y+p_{3} X U-(m+\beta) Y \\
& d Z / d t=p_{2} X Z+p_{4} X U-p_{1}^{\prime} Z Y-p_{3}^{\prime} Z U-(n+\beta) Z \\
& d U / d t=p_{5} X U+p_{1}^{\prime} Z Y+p_{3}^{\prime} Z U-(w+\beta) U
\end{aligned}
$$

It is possible to simplify the model by making two reasonable assumptions. First, the symptoms of $Z$ are much more severe than those of $Y$. With the entry of the mild virus $(Y)$, the symptoms do not change significantly unless there exists some synergism between two viruses. Thus, we have $w \approx n$. Second, dually infected hosts rarely give rise to transmission of the protecting virus alone (i.e., the transition $X \rightarrow Y$ due to $U$ is rare compared with the transition $X \rightarrow Y$ due to $Y$ ). These assumptions are true for both examples we studied. For MAV (moderate) and PAV (virulent), PAV is the stronger competitor within the host plant. That is, if a host plant acquires PAV and MAV at the same time, PAV interferes with MAV replication, leading to lower MAV concentrations in the phloem (53). For CTV, the mild strain also has a low concentration compared to the virulent strain (6). Because of a lack of any synergism between the virus strains, it is expected that the mild strain will occur at a low concentration when sharing a host plant with the virulent strain. With these considerations, $Z$ and $U$ can be merged into one category, $Z$. The category $Z$ was thus redefined as plants infected with the virulent virus alone or with both, and is used in this sense hereafter. The flow chart of the disease system can be simplified (Fig. 1B) and the epidemic system can be represented by the following set of three differential equations:

$$
\begin{aligned}
& d X / d t=(1-q) f-p_{1} X Y-p_{2} X Z-\beta X \\
& d Y / d t=q f+p_{1} X Y-(m+\beta) Y \\
& d Z / d t=p_{2} X Z-(n+\beta) Z
\end{aligned}
$$

The new parameter $p_{2}$ in equations 2 also subsumes $p_{4}$ and $p_{5}$ in equations 1.

For disease systems with continuous crop-host availability in which crop hosts (e.g., perennials) can live many years, we assumed that the total host abundance was kept at a constant $K$ by a planting rate $f=m Y+n Z+\beta K$, thus balancing the losses due to infection and other mortality. By introducing the scaling, $y=Y / K$, $z=Z / K$, and $a=K p_{1}, b=K p_{2}$, equations 2 can be reduced to

$$
\begin{aligned}
& d y / d t=q(m y+n z+\beta)+a(1-y-z) y-(m+\beta) y \\
& d z / d t=b(1-y-z) z-(n+\beta) z
\end{aligned}
$$

where $y$ and $z$ are fractions of the total host population. Equations 3 were used to demonstrate the impact of artificial inoculation on disease outcomes.

The basic reproductive number, $R_{0}(2,32)$, is defined as the number of new infections that arise in a population following the introduction of one diseased individual during that individual's period of infectiousness. For the mild and the virulent viruses, we have $R_{y}=a /(m+\beta)$ and $R_{z}=b /(n+\beta)$, respectively (omitting the subscript 0 to avoid double indices). In the case of infection by a single virus, the virus will persist in the host population provided its basic reproductive number exceeds unity. As we will see later, $R_{0}$ is still a useful quantity to describe the features of epidemics in systems comprising two cross-protecting viruses.

In modeling disease systems with a discontinuous crop host, it was assumed that no host death occurred during the growing season (i.e., $m=n=\beta=0$ ). For BYDVs, the symptoms induced are not so severe that plant death occurs (though loss of infected plants is possible due to competition with more vigorous, healthy plants). The crop hosts are planted and harvested in a very short interval in relation to the growing season and a step function was used to represent this. Following the assumption of Shaw (64), host seasonality was introduced by periodically making a large reduction in the proportion of infected hosts. During the growing seasons, $y$ and $z$ developed according to simple Lotka-Volterra equations

$$
\begin{aligned}
d y / d t & =a(1-y-z) y \\
d z / d t & =b(1-y-z) z
\end{aligned}
$$

During the off seasons, $y$ and $z$ were reduced with an identical rate $\varepsilon<<1$ prior to the start of the next growing season,

$$
\begin{gathered}
y_{s}^{i+1}=\varepsilon y_{e}^{i}+\Delta \\
z_{s}^{i+1}=\varepsilon z_{e}^{i}
\end{gathered}
$$

where the indices $s$ and $e$ refer to the start and the end of growing season and $i$ and $i+1$ refer to previous and present growing seasons,

\begin{tabular}{|c|c|c|c|}
\hline Host transition & $\begin{array}{l}\text { Source of } \\
\text { infection }\end{array}$ & Contact rate & Process \\
\hline $\mathrm{X} \rightarrow Y$ & $Y$ & $p_{1} X Y$ & Protecting virus is transmitted from plants infected by protecting virus alone to healthy plants. \\
\hline$Z \rightarrow U$ & $Y$ & $p_{1}^{\prime} Z Y$ & $\begin{array}{l}\text { Protecting virus is transmitted from plants infected by protecting virus alone to plants infected by } \\
\text { challenging virus alone. }\end{array}$ \\
\hline$X \rightarrow Z$ & $Z$ & $p_{2} X Z$ & Challenging virus is transmitted from plants infected by challenging virus alone to healthy plants. \\
\hline$X \rightarrow Y$ & $U$ & $p_{3} X U$ & Protecting virus is transmitted from dually infected plants to healthy plants. \\
\hline$Z \rightarrow U$ & $U$ & $p_{3}^{\prime} Z U$ & Protecting virus is transmitted from dually infected plants to plants infected by challenging virus. \\
\hline$X \rightarrow Z$ & $U$ & $p_{4} X U$ & Challenging virus is transmitted from dually infected plants to healthy plants. \\
\hline$X \rightarrow U$ & $U$ & $P_{5} X U$ & Both viruses are simultaneously transmitted from dually infected plants to healthy plants. \\
\hline
\end{tabular}
respectively. Here, $\Delta$ represents the proportion of new planting that is artificially inoculated at the start of the growing season.

The first item, " $\varepsilon y$ " (and " $\varepsilon z$ "), denotes the natural carryover of infection from the previous crop. This actually occurs through the arrival of infective vectors over a period in the early stages of crop growth. Thus, if $\Delta=100 \%, y_{s}^{i+1}=1$ and $z_{s}^{i+1}=0$ and subsequent natural infection cannot occur. For simplicity, we represent these two items as occurring independently, and $\Delta$ is assumed to be less than or equal to $1-\varepsilon y_{e}^{i}$. This is reasonable, because we show later that the critical level of artificial inoculation is always sufficiently small.

TABLE 3. Possible transitions between four different host infection categories in a pathosystem where cross protection occurs between one virus and another 
For a continuous crop host, equilibria were obtained analytically and numerically by setting each of the equations to zero and letting the epidemic system develop to a steady state, respectively. For a discontinuous crop host, the change in incidence from one season to the next was examined analytically and the longterm outcome obtained by simulation. Modelmaker (version 3.0; Cherwell Scientific, Oxford) was used for numerical work.

Parameter estimation. Transmission rates were estimated indirectly by comparing experimental observations of disease incidence with the logistic equation, $d u / d t=r u(1-u)$, in which $u$ represents the proportion of plants which are diseased and $r$ the transmission rate. For CTV, transmitted by aphids, field data (12) showed that, in a period of 10 years, the incidence of CT disease in an orchard progressed from less than 1 to $76 \%$. The transmission rate was therefore estimated to be $\approx 0.0018$ day $^{-1}$. Virulent and mild strains differed markedly in their transmissibility by $A$. gossypii. High transmission efficiencies, averaging $40 \%$, were obtained with the virulent strain, compared with less than $5 \%$ with the mild strain (6). Here, 40 and 5\% refer to the percentage of plants infected in inoculation tests with aphids. Estimates of $b=0.0018 \mathrm{day}^{-1}$ for the virulent and $a=0.0002 \mathrm{day}^{-1}$ for the mild were used to reflect this observation. Following the method of Chan and Jeger (16) and from observations of CT $(8,9)$, the loss rate due to infection with severe strains of CTV can be estimated as $\approx 1 / 8$ per year $\left(\approx 0.00034\right.$ day $\left.^{-1}\right)$. Compared to the virulent strain, the mild strain of CTV caused mild symptoms and the loss rate due to the mild strain was estimated to be about $20 \%$ that of the virulent strain (i.e., $m=0.00007$ day $^{-1}$ ). The natural mortality can be estimated $(16)$ as $1 / 50$ per year $\left(\approx 0.00005\right.$ day $\left.^{-1}\right)$.

The growing season of winter cereals was taken to be $\approx 9$ months in Northern Europe and North America and the typical final incidence of BYDV disease can range from 5 to $20 \%(26,42,50)$. The transmission rate, therefore, was estimated to be $\approx 0.024$ day $^{-1}$. PAV can be transmitted by aphids $R$. padi, Sitobion avenae, and Schizaphis graminum, but MAV only by Sitobion avenae. The vector Sitobion avenae predominates and $R$. padi is also quite common; the relative abundance of the two aphid species has not changed over 20 years (1957 to 1976) (58) and PAV, therefore, may have a potentially greater vector population. It has also been suggested that the ecology of these vectors (e.g., movement behavior, production of winged aphid morphs) favors PAV transmission. These facts suggest the relationship $b>a(53)$.

\section{RESULTS}

Disease systems with continuous crop-host availability. Two different strategies of artificial inoculation $(q)$ are considered: fixed proportion (i.e., $q$ is an independent parameter within the range $0 \leq$ $q \leq 1$ ) and disease-dependent proportion (i.e., $q$ depends on current disease incidence such that $q=\rho z$, with $0<\rho \leq 1)$. The results are shown in Tables 4 and 5 and Figures 2 and 3 . The derivation of the stability conditions of the equilibria is given in Appendix A.

Fixed proportion. With no artificial inoculation, only healthy plants are planted (i.e., $q=0$ ) and the development and outcome of the disease system is determined exclusively by the characteristics of infection dynamics. In this situation, equation 3 reduces to the well-known Lotka-Volterra competition equations $(15,38)$. The "competitive exclusion principle" thus applies and the virus with a higher $R_{0}$ will outcompete the other (11). Unlike the situation in the single virus system, however, the condition $R_{0}>1$ does not guarantee virus persistence and a virus will be eliminated if the other virus's $R_{0}$ is greater. This was illustrated in Figure $2 \mathrm{~A}$, where the loss rate due to infection with the virulent virus was nearly five times higher than that with the mild virus, $n / m \approx 5$, but the virulent virus was transmitted nine times more efficiently than the mild virus, $b / a=9$. The mild virus declined even with $R_{y}>1$, whereas because $R_{z}>R_{y}$, the virulent virus quickly increased and eventually excluded the mild virus.
Another special case is that where all new planting material is artificially inoculated (i.e., $q=1$ ). The only outcome drawn from the model is the equilibrium: $y^{*}=1$ and $z^{*}=0$. That is, the virulent virus will be eliminated and the entire host population will become infected with the mild virus. This outcome is totally independent of the characteristics of infection dynamics.

An important question concerns the extent of managed cross protection required to achieve adequate disease control. The investigation of a situation where $0<q<1$ shows there exists a critical level of artificial inoculation, $q_{c}$, above which the virulent virus can be excluded. Below this critical level, both the mild and the virulent viruses coexist. The minimum level of artificial inoculation to achieve disease elimination is determined exclusively by the characteristics of the infection dynamics, and

$$
q_{c}=\frac{R_{z}-1}{R_{z}-m /(m+\beta)}\left(1-\frac{R_{y}}{R_{z}}\right)
$$

(Table 4; Appendix A). When $y$ is large, the opportunity for $z$ to increase will be quite small because few susceptible host plants are available. If the extent of artificial inoculation is larger than $q_{c}$, the proportion $y$ is maintained at a high level, such that the
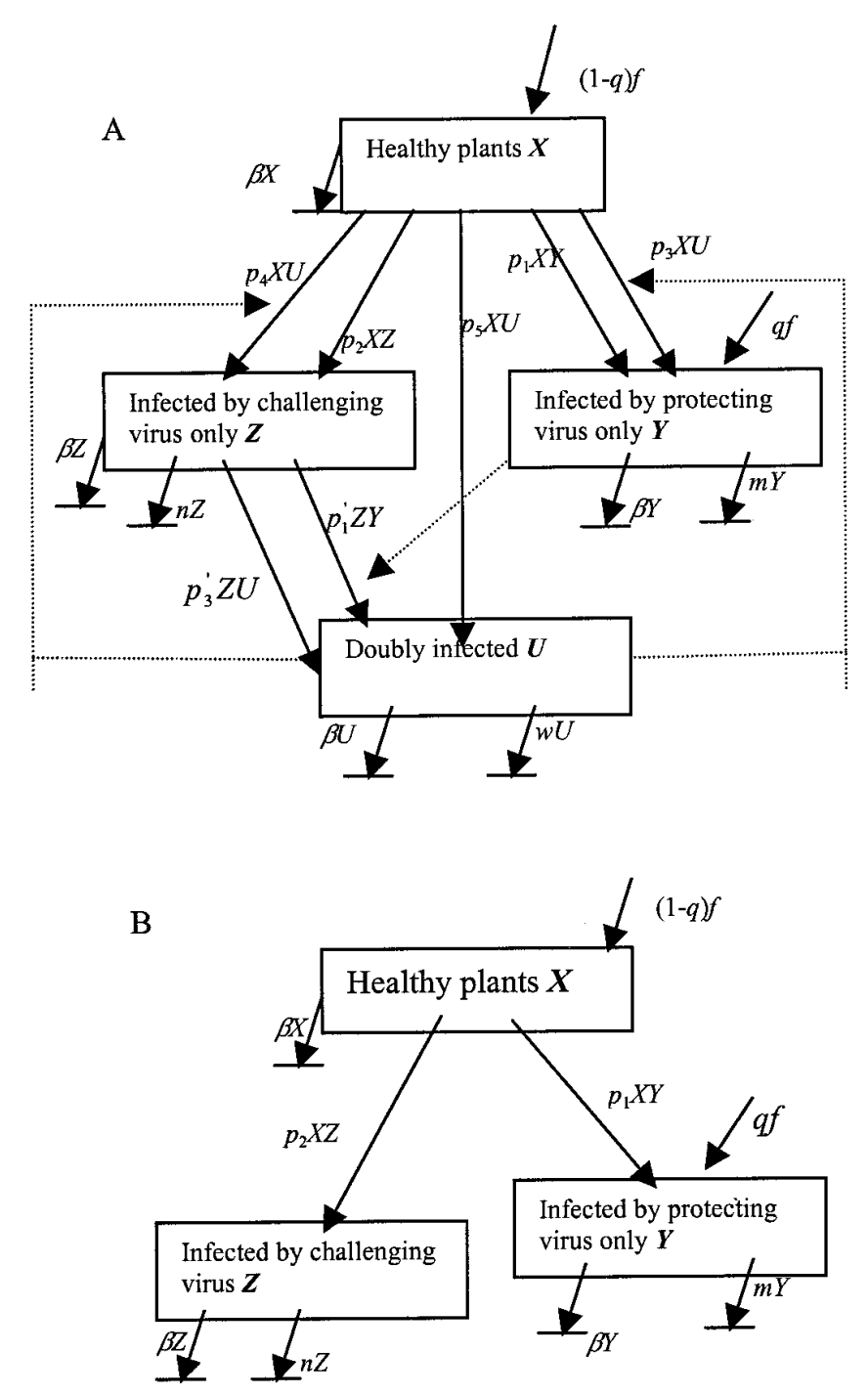

Fig. 1. Flow chart of the model of host infection where cross protection occurs between one virus and another. A, General situation; $\mathbf{B}$, simplified case, in which the new parameter $p_{2}$ also subsumes $p_{4}$ and $p_{5}$ such that host category $U$ has been merged with $Z$. Solid arrows indicate transitions; dotted arrows indicate influences. Variables and parameters are explained in Table 6. 
decrease in $z$ due to natural mortality and disease is greater than the increase due to transmission. This certainly leads to the elimination of $z$. If $R_{y}>R_{z}$, then no artificial inoculation is required to control the severe virus $\left(q_{c}<0\right)$. Under the extreme situation $R_{y}=0$, the critical level, $q_{c}=\left(R_{z}-1\right) /\left[R_{z}-m /(m+\beta)\right]<1$ if $\beta>0$. This is because natural mortality imposes a loss on $z$, and the extent of the mild infection required to eliminate $z$ is thus a little lower than that in the absence of natural mortality (when $q_{c}=1$ ). With some natural mortality, therefore, the critical level is always less than $100 \%$. At the critical level of artificial inoculation, we have at equilibrium, $y_{c}^{*}=1-[(n+\beta) / b]=1-\left(1 / R_{z}\right)$ and $z_{c}^{*}=0$. This implies that it is not necessary for all new planting materials to be cross protected to achieve disease eradication.

For CTV, with the infection parameters estimated above, the critical level is $q_{c} \approx 0.57$. The consequences of different levels of managed cross protection are shown in Figure 2B $\left(q<q_{c}\right)$ and

TABLE 4. Equilibria and stability conditions of disease epidemic outcomes where artificial inoculation of a protecting virus occurs as a fixed proportion of new planting material

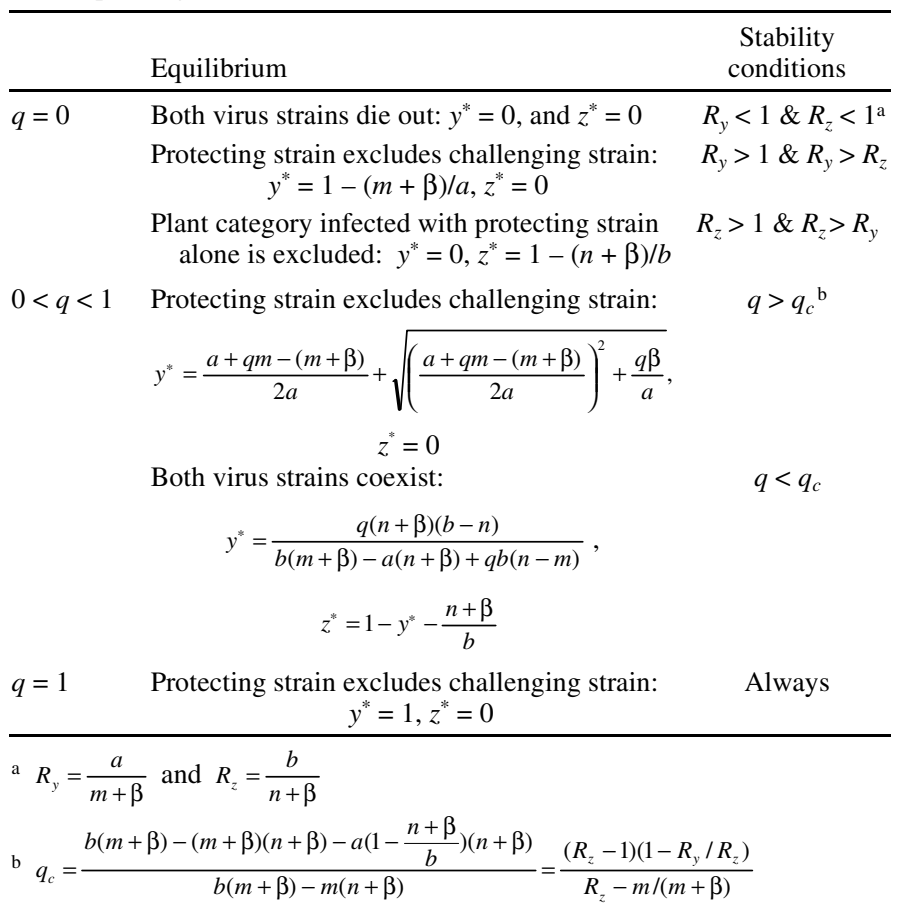

TABLE 5. Equilibria and stability conditions of disease epidemic outcomes where artificial inoculation of a protecting virus occurs as a diseasedependent proportion of new planting material

\begin{tabular}{lc}
\hline Equilibrium & $\begin{array}{c}\text { Stability } \\
\text { conditions }\end{array}$ \\
\hline Both virus strains die out: $y^{*}=0$, and $z^{*}=0$ & $R_{y}<1 \& R_{z}<1$ \\
Protecting strain excludes challenging strain & $R_{y}>1 \& R_{y}>R_{z}$ \\
$y^{*}=1-\frac{m+\beta}{a}$, and $z^{*}=0$ & $R_{z}>1 \& R_{z}>R_{y}$ \\
Both virus strains coexist ${ }^{\mathrm{a}, \mathrm{b}}$ & \\
$y^{*}=\Omega_{1}-\sqrt{\Omega_{1}^{2}-\Omega_{2}}$, and $z^{*}=1-y^{*}-\frac{n+\beta}{b}$ &, and \\
a $\Omega_{1}=\frac{\rho[2 n(b-(n+\beta))+b(\beta-m)+m(n+\beta)]-a(n+\beta)+b(m+\beta)}{2 \rho b(n-m)}$ & $(n+\beta)(b-n)\left(1-\frac{n+\beta}{b}\right)$ \\
$\Omega_{2}=\frac{(n-m)}{2}$
\end{tabular}

${ }^{\mathrm{b}}$ As $\rho$ increases, $\Omega_{1}$ decreases, $y^{*}$ will increase and thus $z^{*}$ will decrease under the circumstance $R_{z}>R_{y}$. However, the value $\rho=1$ cannot guarantee $z^{*}=0$.
Figure 2C $\left(q>q_{c}\right)$. As the level of artificial inoculation (i.e., $\left.q\right)$ increases, disease incidence will be depressed, and mild infections increase. As $q$ exceeds the critical value 0.57 , the virulent virus will be eliminated in the long run (Fig. 3). It is interesting to note that, at equilibrium, not all the host plants are necessarily infected with the protecting virus: $\approx 80 \%$ in this example, with the rest $(\approx 20 \%)$ being virus-free. It seems possible, on purely intuitive grounds, that the virulent virus could reinvade the host population. In practice, this invasion would not be successful because, with artificial inoculation $q>q_{c}, y$ has a sufficiently high incidence at equilibrium so that, for the virulent virus, losses exceed new infections and $z$ can only decline in the long term.

Another interesting point illustrated in Figure 2 is that, prior to the control of a virulent virus, there is an opportunity for a disease outbreak. This may mean that the level of artificial inoculation employed cannot match the rapid spread of the virulent virus in a
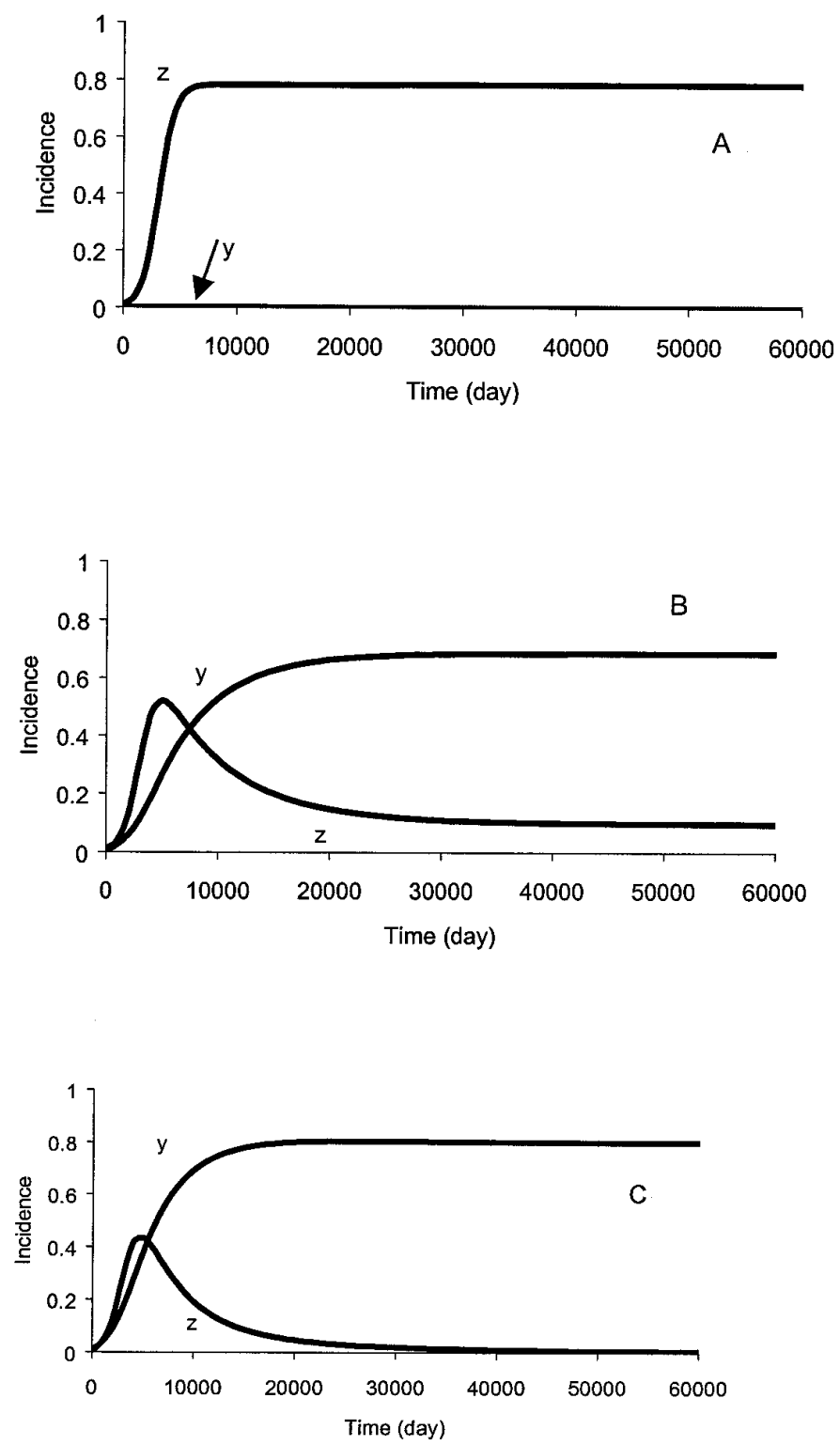

Fig. 2. Numerical results from equations 3 with the parameters for the mild virus strain: $a=0.0002 \mathrm{day}^{-1}, m=0.00007 \mathrm{day}^{-1}$; the virulent virus strain: $b=0.0018$ day $^{-1}, n=0.00034$ day $^{-1}$; and the natural host mortality $\beta=$ 0.00005 day $^{-1}$. Thus, $R_{z}(=4.6)>R_{y}(=1.7) ; y_{0}=0.001$ and $z_{0}=0.01$. The proportion $q$ of new planting material inoculated with the protecting mild virus: $\mathbf{A}, 0, \mathbf{B}, 0.4$, and $\mathbf{C}, 0.6$. 
short term. However, disease incidence will be curtailed or eliminated entirely if the managed cross protection is maintained.

Disease-dependent proportion: $q=\rho z(0<\rho \leq 1)$. In this scenario, the extent of managed cross protection depends on the current disease incidence so that, when disease incidence is high, a correspondingly greater degree of artificial inoculation is employed. When disease incidence reduces, so does artificial inoculation. The equilibria and their stability conditions under this strategy are illustrated in Table 5. It can be seen that the stability conditions of the equilibrium are independent of the parameter $\rho$. Hence, this "responsive" strategy cannot alter the persistence of the virulent virus. However, this approach can maintain disease incidence at a low level.

Disease systems with discontinuous crop-host availability. The investigation of the virus persistence criterion for an epidemic of a single virus (Appendix B) shows that the virus can persist in a seasonal host population if $\exp (b T)>1$, where $T$ is the duration of the growing season. This requirement has the intuitively reasonable interpretation that the incidence at the start of each growing season should not be less than that of the previous growing season. Interestingly, this virus persistence criterion varies with exponents of $b$ and $T$ but linearly with $\varepsilon$, which implies that changes in $b$ and $T$ are more influential than $\varepsilon$ in determining disease incidence. A decrease in transmission can therefore have more impact on disease incidence than a reduction in the size of the "green bridge" (66) between growing seasons.

First, let us discuss the situation where no artificial inoculation of the protecting mild virus is introduced (i.e., $\Delta=0$ ). Within an epidemic of two cross-protecting viruses, the following relationship can be obtained from equations $4 \mathrm{a}$,

$$
\frac{d z}{z}=\frac{b}{a} \frac{d y}{y}
$$

This applies to the growing season and holds only if $1-y-z>0$ (i.e., before disease saturation). Integration of equation 6 a can give rise to a relationship: $y \propto z^{a / b}$, which directly leads to

$$
\frac{y_{e}}{y_{s}}=\left(\frac{z_{e}}{z_{s}}\right)^{a / b}
$$

If $b>a$, the following relationships can be drawn from equation 6b: $y_{e} / y_{s}<z_{e} / z_{s}$, hence $y_{e} /\left(z_{e}+y_{e}\right)<y_{s} /\left(z_{s}+y_{s}\right)$ and $z_{e} /\left(z_{e}+y_{e}\right)>$ $z_{s} /\left(z_{s}+y_{s}\right)$. That is, if the virulent virus has a higher overall transmission rate than the mild virus, the relative proportion of the virulent virus will increase through each growing season, assuming $\varepsilon$ is fixed for $y$ and $z$. The virulent virus will predominate while the mild will disappear at the end of a period of competition. This result is independent of the initial relative proportion. If $b<a$, the opposite outcome will occur. Without artificial

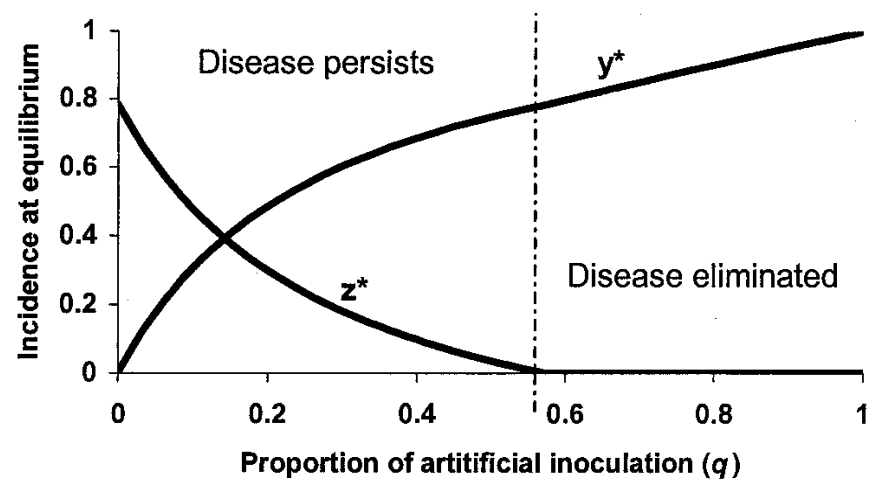

Fig. 3. Impact of the proportion of planting material artificially inoculated with the protecting virus $q$ on the incidences, at equilibrium, of the protecting $y$ and challenging $z$ viruses. Parameters for the mild virus strain: $a=$ 0.0002 day $^{-1}, m=0.00007$ day $^{-1}$; the virulent virus strain: $b=0.0018$ day $^{-1}$, $n=0.00034$ day $^{-1} ;$ and the natural host mortality $\beta=0.00005$ day $^{-1}$. Thus, $R_{z}$ $(=4.6)>R_{y}(=1.7) ; y_{0}=0.001 ;$ and $z_{0}=0.01$. inoculation, therefore, the outcome depends solely upon the transmission rates. Because both cross protection and seasonal reduction occur in this model disease system, the two persistence criteria for the challenging virus are $b>a$ and $\varepsilon \exp (b T)>1$. These results were supported by numerical experiments.

It is interesting to compare the results from the modeling with examples of field data. In the data of Rochow (58), all five BYDVs were recorded in New York State from 1957 to 1976. Ignoring the other BYDVs which fluctuated at low levels and did not display any long-term trends (58), the gradual change in the relative proportions of MAV and PAV can be fitted to the model by optimizing the transmission rates in equations 4 a to $a=0.0226$ day $^{-1}$ and $b=0.0240$ day $^{-1}$. Due to the rarity of mixtures of MAV and PAV, $z$ can be regarded as the incidence of PAV. The theoretical fitted curves are in agreement with the field data from New York State for 1957 to 1976 (Fig. 4). The historical shift in virus dominance was thus explained theoretically by postulating only a slightly higher transmission rate for PAV than for MAV.

Various factors affect both transmission and loss rates. For example, virus spread has been correlated with vector population
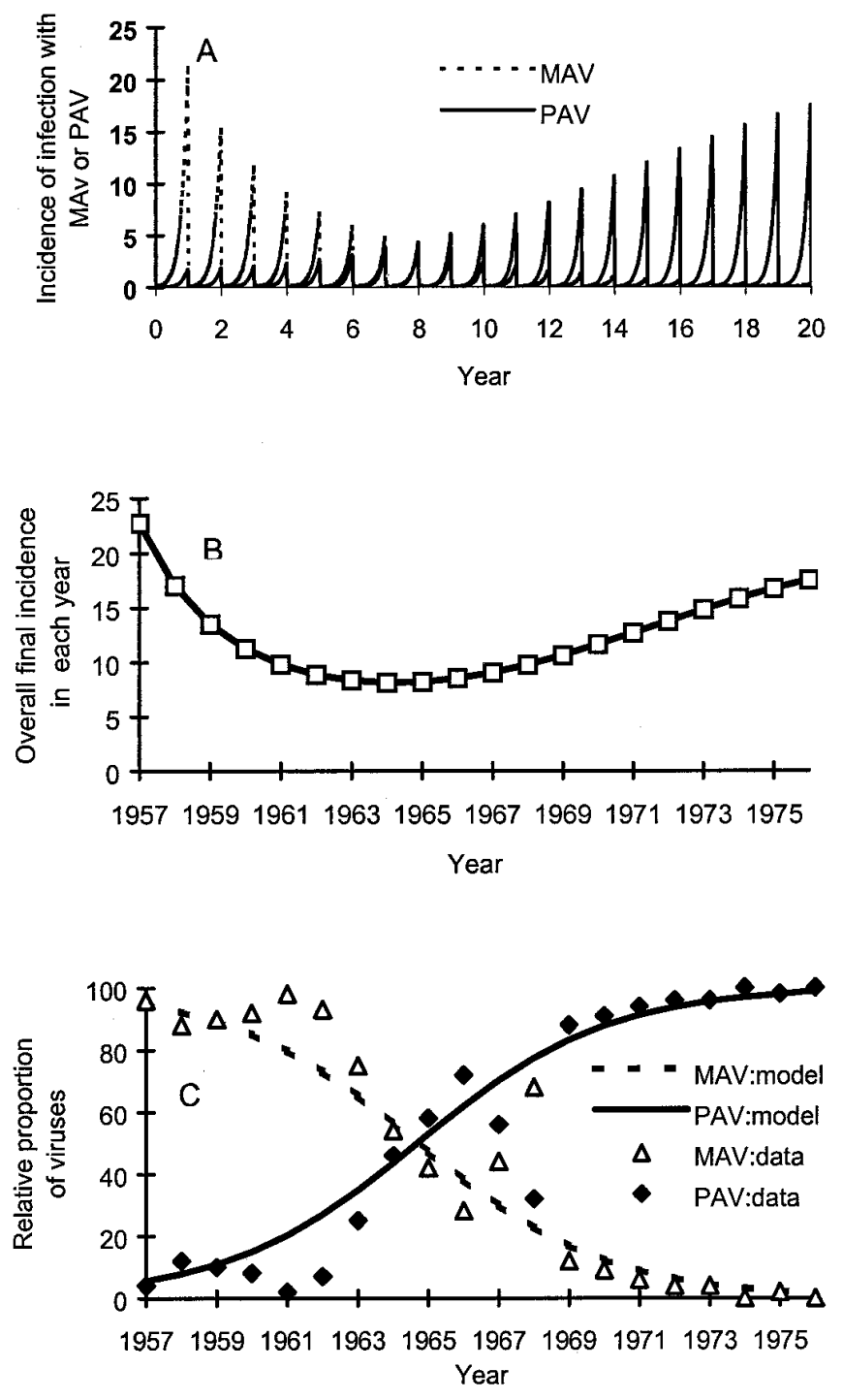

Fig. 4. Numerical results from equations $4 \mathrm{a}$ and $4 \mathrm{~b}$ for a discontinuous crophost with the parameters: $a=0.0226 \mathrm{day}^{-1}, b=0.024 \mathrm{day}^{-1}, \varepsilon=0.0025, m=$ $n=0$, and initial values $y_{s}^{0}=0.00068(0.068 \%), z_{s}^{0}=0.00004(0.004 \%)$. $\mathbf{A}$, Changes in incidence of the two viruses over 20 growing seasons; $\mathbf{B}$, total final incidence at the end of the growing season; and $\mathbf{C}$, gradual change in the relative proportions of the viruses compared with field data $(42,58)$. 
size, and the number of aphids flying to cereal plants varied during the year (50). Aphid transmission efficiency was affected by temperature (56). It is recognized, therefore, that the parameters in the model are not constants but change over time. Such fluctuation in parameter values may lead to the fluctuation in relative incidence seen in the field data (Fig. 4C).

The overall incidence at the end of each growing season (Fig. $4 \mathrm{~A}$ and $\mathrm{B}$ ) indicated that the strongest competition existed when the two viruses occurred in similar proportions, because this situation resulted in the lowest overall final incidence. When two cross-protecting viruses share the same host population, competition occurs because the host available to each decreases.

\section{DISCUSSION}

The models developed here describe the infection dynamics associated with cross protection in plant-virus disease systems. Vectors were not explicitly represented in the models, so the conventional bilinear terms were used to model host infection. This is an important simplification, given the large variation of vector population size during the cropping period and influence of changing climatic, environmental, and other factors on the vectors. Interactions among virus, host, and vector can occur, resulting in vector aggregation on diseased plants. In this case, transmission rates depend on disease incidence (68). Further, interactions between viruses may differ in the vector and the host, potentially making the infection rates very complicated functions of all factors involved. The deviation between a bilinear infection rate and some more complicated rate may not, however, be significant, especially when the vector abundance is not large (68), and a bilinear infection rate is a reasonable starting point. Clearly, however, incorporating vector population dynamics in models can increase our understanding of plant-virus disease epidemics (32). The same is likely to be true for models involving virus-virus interactions and so deserves further investigation, despite the inevitable decrease in the tractability of the mathematical analysis.

Two different disease systems were recognized according to continuity in crop-host availability. Interesting comparisons can be made between the two systems in the conditions for virus persistence. For an epidemic of a single virus, it is well known that the criterion for virus persistence with a continuous host is $R_{0}>1$. In this article, we show that, with a discontinuous host, the criterion changes to $\exp (b T)>1$. The inclusion of seasonality, therefore, increases the barrier for a virus to persist. For epidemics of two cross-protecting viruses under natural infection dynamics, the criteria for the mild virus to persist with a continuous host are $a / m>b / n$ and $a / m>1$, but with a discontinuous host they become $a>b$ and $\exp (a T)>1$. This difference occurs because an equilib-

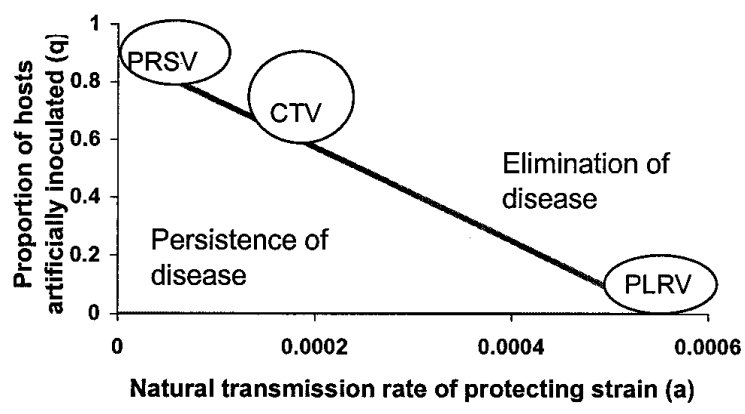

Fig. 5. Dependence of the critical level of artificial inoculation $q_{c}$ required to achieve disease elimination (i.e., $z^{*}=0$ ) on the natural transmission rate of the mild virus $a$. The situation pertaining for three examples of cross protection is illustrated. Parameters for the mild virus strain: $a=0.0002$ day $^{-1}, m=$ $0.00007 \mathrm{day}^{-1}$; the virulent virus strain: $b=0.0018 \mathrm{day}^{-1}, n=0.00034 \mathrm{day}^{-1}$; and the natural host mortality $\beta=0.00005$ day $^{-1}$. Thus, $R_{z}(=4.6)>R_{y}$ $(=1.7) ; y_{0}=0.001 ;$ and $z_{0}=0.01$. rium can be reached in the former but not in the latter, and loss terms due to infections are present in the former but not in the latter. The differences are thus partly due to the simplified nature of the models, particularly the latter.

With the utilization of deliberate cross protection, the outcome for host infection will be changed. Within a disease system where the virulent virus naturally predominates, there exists a critical level of artificial inoculation of the protecting mild virus above which the virulent virus will be controlled. Below this critical level, the two viruses coexist. Investigations of both pathosystem types demonstrated the same qualitative result that managed cross protection need not be $100 \%$, but must be maintained even when disease incidence declines. A general difference between the two types of pathosystem lies in the critical level of cross protection required to eradicate the disease: high for continuous and very low for discontinuous. The seasonal reduction in disease incidence associated with the discontinuous system has a very important impact in this respect. The prediction of much lower $q_{c}$ value for annual than for perennial crops may in part be the consequence of model simplification, and further work is required. Indeed, carryover of host infection from one season to the next may also differ between the two viruses concerned. Density or frequency dependence in carryover may lead to phenomena such as initial dependence (29).

Disease systems with continuous crop-host availability. In principle, evolution would not be expected to lead to a virus with high virulence and low transmission rate (52). Virulent strains are often found to have higher titers than mild ones and, therefore, can be easily transmitted (e.g., CTV [6], Cacao swollen shoot virus [51], and Papaya ringspot virus [67]). There is usually a correlation between virulence and transmissibility. The mild strains of CTV may have been the first to establish in Brazil but virulent strains that invaded from Africa and South America in the 1920s predominated within less than two decades because they have higher transmission rates by aphids $(5,6,25,62)$. There may be some exceptions in which vectors more readily transmit the mild strain than the virulent strain (e.g., in the case of Potato leaf roll virus) (24). Under this circumstance, $R_{y}>R_{z}$ may occur, offering possible evidence that cross protection against a virulent virus by a mild virus operates in nature: "The reason why an outstanding variety of potato like Up-to-Date resists degeneration so long is that the whole clone became infected by chance with a mild strain which protects it from more severe strains of this virus" $(19,46)$.

An increase in the natural transmission rate of the protecting mild virus (e.g., by a change in vector genotype) (35), can reduce the critical level $q_{c}$ and thus help disease control. The critical level $q_{c}$ decreases linearly as the natural transmission rate of the protecting virus, $a$, increases. Thus, there is a direct trade-off between the two possible methods for disease control: increasing the natural transmission rate of the protecting mild virus and increasing the level of artificial inoculation. Suppose that a mild virus can effectively protect host plants against infection with a virulent virus but has a very poor capability to be transmitted naturally. The successful control of the disease would rely mainly on a very high level $(\approx 100 \%)$ of artificial inoculation. This may be the situation for papaya ringspot disease, in which the protecting mild strain was obtained by artificial methods $(19,67)$. If, on the other hand, a protecting mild virus can be readily transmitted by vectors, then a lower level of artificial inoculation can control the disease effectively. The example of CTV described above belongs to this situation, where the protecting strain is a naturally occurring variant isolated directly from plants with mild symptoms in the field (17). When the natural transmission rate $a$ is so large that $R_{y}$ is greater than $R_{z}$, the critical level $q_{c}$ is zero. This may apply to the case of Potato leaf roll virus (24). The relationship between $q$ and $a$, along with approximate relative positions of the three examples discussed above, is illustrated in Figure 5. The combined effect of increasing both the natural transmission rate $a$ and the 
level of artificial inoculation can increase the opportunities to achieve the outcome illustrated in Figure 2C. Clearly, any mechanism to enhance the transmission of the protecting virus would need to be highly selective.

Considering the most effective strategy of artificial inoculation, a fixed inoculation rate is better than one determined by the current disease level. The disease-dependent strategy could reduce the disease incidence but cannot eradicate the disease. Thus, cross protection should not be reduced when disease incidence is low. Although a grower may inoculate all new planting materials with a mild strain, the inoculation success may be less than $100 \%$. Within a locality, mild strain protection may be practiced only by some growers. The results of this study show that effective disease control may still be possible under such circumstances. Light is shed, therefore, on the common fact that a disease has been controlled even though experiments illustrate the possibility of breakdown of protection in challenged plants $(7,18)$.

Disease systems with discontinuous crop-host availability. The model studied here provided a possible explanation for the historic change in the predominant virus from MAV to PAV in New York State since 1957 (42,58). Cross protection between MAV and PAV leads to a faster relative increase for PAV, which has a larger transmission rate (equation 6a) during each growing season. Seasonal reduction in host abundance (equations $4 \mathrm{~b}$ with $\Delta=0$ ) greatly reduces the total incidence as new susceptible host plants are introduced at the start of each growing season. Each virus has a chance to increase again and accumulate a different $y_{s}$ or $z_{s}$ to start the following season. This process of increase
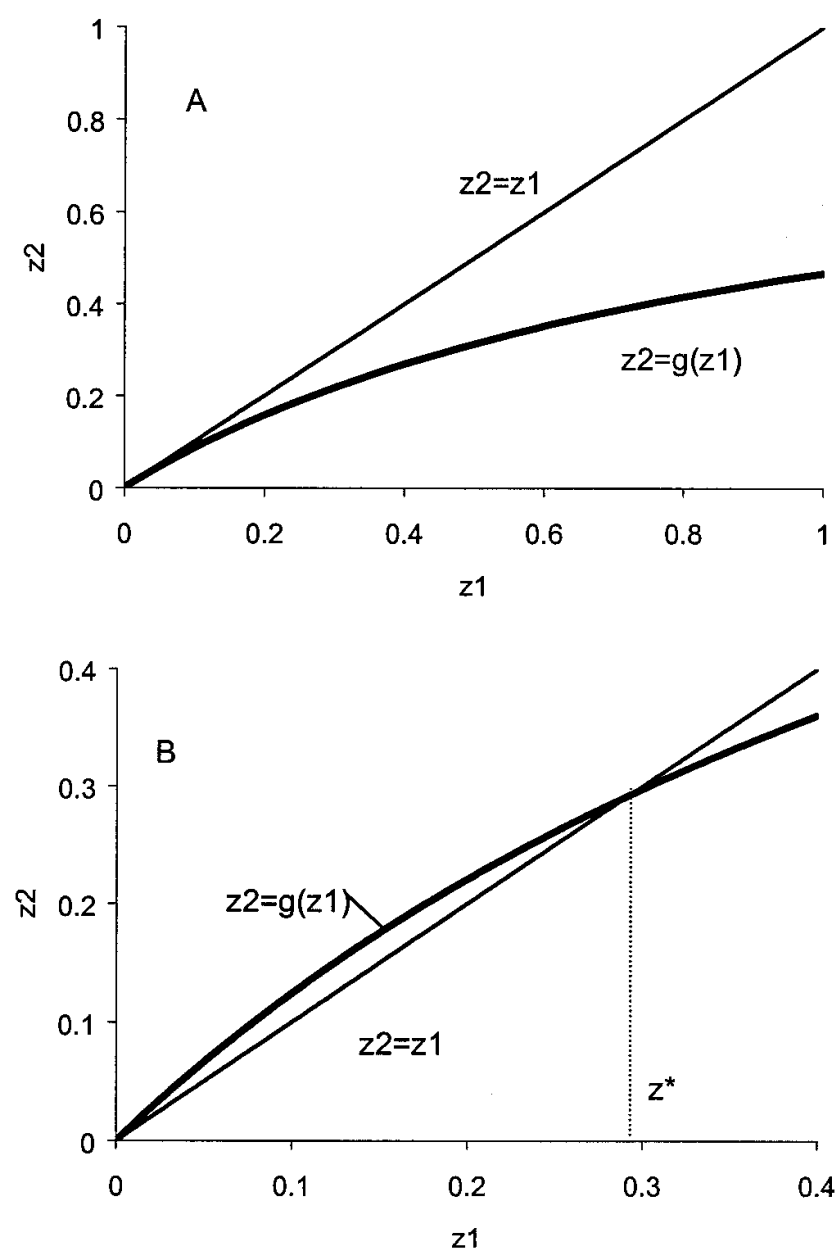

Fig. 6. Illustrations of behaviors of the function $z_{2}=g\left(z_{1}\right)$ (Appendix B) where the virus $\mathbf{A}$, does not persist, $\exp (b T)<1$; and $\mathbf{B}$, persists, $\varepsilon \exp (b T)>1$. followed by curtailment allows the more competitive virus to predominate while its competitor declines. The combination of these two aspects, therefore, provides a mechanism of replacement of MAV by PAV in New York State.

Cross protection between viruses occurs naturally in BYDV but a number of examples of artificial cross protection also exist in annual crops (e.g., Zucchini yellow mosaic virus) (34). The disease outcome at equilibrium may differ from that without artificial inoculation. With artificial inoculation at planting, the outcomes of disease systems were determined also by the level of artificial inoculation. As in disease systems with continuous crophost availability, there is a critical level of artificial inoculation above which the virulent virus is excluded. Below this critical level, the two viruses coexist (X.-S. Zhang and J. Holt, unpublished data). This critical level is determined by both transmission rates and the seasonal reduction rate $(\varepsilon)$. For BYDV, this critical level is very low $(\approx 0.04 \%)$, which means, were it feasible, a little effort could change the natural process in which PAV replaced MAV. This is because the transmission rate of MAV is very close to that of PAV. If the protecting virus is poorly vector-transmitted, say, $a=b / 20$, then $\approx 7 \%$ artificial inoculation at planting will be required to control the virulent virus in the long run. A similar relationship between artificial inoculation and natural transmission rate of the protecting virus can be obtained in the discontinuous system as in the continuous system (X.-S. Zhang and J. Holt, unpublished data). With the discontinuous system, it is also true that managed cross protection need not be $100 \%$ for disease eradication to be achieved. The critical levels of artificial

TABLE 6. Definition of symbols (glossary)

\begin{tabular}{|c|c|c|}
\hline Variable & Description & Dimensions \\
\hline$X$ & Abundance of healthy plants & {$[$ Plant $][\text { area }]^{-1}$} \\
\hline Y & $\begin{array}{l}\text { Abundance of plants infected by the } \\
\text { protecting virus alone }\end{array}$ & {$[$ Plant $][\text { area }]^{-1}$} \\
\hline$Z$ & $\begin{array}{l}\text { Abundance of plants infected by the } \\
\text { challenging virus alone or both }\end{array}$ & {$[$ Plant $][\text { area }]^{-1}$} \\
\hline$U$ & Abundance of dually-infected plants & {$[$ Plant $][\text { area }]^{-1}$} \\
\hline$y$ & $\begin{array}{l}\text { Fraction of the total population } \\
\text { infected with the protecting virus }\end{array}$ & Dimensionless \\
\hline$z$ & $\begin{array}{l}\text { Fraction of the total population } \\
\text { infected with the challenging virus }\end{array}$ & Dimensionless \\
\hline$y_{e}^{i}, z_{e}^{i}$ & $\begin{array}{l}\text { Incidence at the end of growing } \\
\text { season of year } i\end{array}$ & Dimensionless \\
\hline$y_{s}^{i+1}, z_{s}^{i+1}$ & $\begin{array}{l}\text { Incidence at the start of growing } \\
\text { season of year } i+1\end{array}$ & Dimensionless \\
\hline \multicolumn{3}{|l|}{ Parameter } \\
\hline$p_{1} \ldots p_{5}$ & Transmission rates (Table 3) & $\left.\mathrm{t}][\text { area }]^{-1}\right]^{-1}[\text { time }]^{-}$ \\
\hline$a$ & $\begin{array}{l}\text { Transmission rate of the protecting } \\
\text { virus }\end{array}$ & {$[\text { Time }]^{-1}$} \\
\hline$b$ & $\begin{array}{l}\text { Transmission rate of the challenging } \\
\text { virus }\end{array}$ & {$[\text { Time }]^{-1}$} \\
\hline$m$ & $\begin{array}{l}\text { Loss rate due to single infection with } \\
\text { the protecting virus }\end{array}$ & {$[\text { Time }]^{-1}$} \\
\hline$n$ & $\begin{array}{l}\text { Loss rate due to single infection with } \\
\text { the challenging virus }\end{array}$ & {$[\text { Time }]^{-1}$} \\
\hline$w$ & Loss rate due to double infection & {$[\text { Time }]^{-1}$} \\
\hline$\beta$ & Rate of natural host mortality & {$[\text { Time }]^{-1}$} \\
\hline$R_{y}$ & $\begin{array}{l}\text { Basic reproductive number of the } \\
\text { protecting virus }\end{array}$ & Dimensionless \\
\hline$R_{z}$ & $\begin{array}{l}\text { Basic reproductive number of the } \\
\text { challenging virus }\end{array}$ & Dimensionless \\
\hline$K$ & Maximum plant abundance & {$[$ Plant $][\text { area }]^{-1}$} \\
\hline$f$ & Host planting rate & {$[$ Plant $][\text { area }]^{-1}[\text { time }]^{-1}$} \\
\hline$q$ & $\begin{array}{l}\text { Proportion of new planting materials } \\
\text { that are artificially inoculated with } \\
\text { the protecting mild virus }\end{array}$ & Dimensionless \\
\hline$\varepsilon$ & $\begin{array}{l}\text { Proportional reduction in disease inci- } \\
\text { dence from end of previous grow- } \\
\text { ing season to the start of the present }\end{array}$ & Dimensionless \\
\hline$\Delta$ & $\begin{array}{l}\text { Proportion of new planting which is } \\
\text { artificially inoculated at the start } \\
\text { of growing season }\end{array}$ & Dimensionless \\
\hline
\end{tabular}


inoculation for discontinuous systems are generally much less than those for continuous systems. The rate at which a disease is eradicated is, of course, correlated with the level of artificial inoculation and the higher the level of artificial inoculation, the sooner the disease is controlled.

\section{APPENDIX A}

Stability analysis of equations 3. The equilibria and stability conditions for a disease system with continuous crop-host availability are listed in Tables 4 and 5. Here we derive the stability conditions when $0<q<1$ (Table 4 ). The stability conditions for $q=0$ and $q=\rho z$ (Table 5) can be similarly obtained. Their derivations are omitted here.

The stability of the equilibrium of equations 3 depend on the eigenvalues of the community matrix

$$
A=\left(\begin{array}{ll}
\frac{\partial \dot{y}}{\partial y} & \frac{\partial \dot{y}}{\partial z} \\
\frac{\partial \dot{z}}{\partial y} & \frac{\partial \dot{z}}{\partial z}
\end{array}\right)=\left[\begin{array}{cc}
a(1-2 y-z)-(m+\beta)+m q & -a y+n q \\
-b z & b(1-y-2 z)-(n+\beta)
\end{array}\right]_{y^{*}, z^{*}}
$$

For the first equilibrium, where the virulent virus strain dies out,

$$
y^{*}=\frac{a+q m-(m+\beta)}{2 a}+\sqrt{\left(\frac{a+q m-(m+\beta)}{2 a}\right)^{2}+\frac{q \beta}{a}} \text { and } z^{*}=0
$$

The eigenvalues are given as

$$
\begin{aligned}
& \lambda_{1}=a\left(1-2 y^{*}\right)-(m+\beta)+m q=-2 a \sqrt{\left(\frac{a-(m(1-q)+\beta)}{2 a}\right)^{2}+\frac{\beta q}{a}}<0 \\
& \lambda_{2}=a\left(1-y^{*}\right)-(n+\beta)=\frac{a b+b(m(1-q)+\beta)}{2 a}-b \sqrt{\left(\frac{a-(m(1-q)+\beta)}{2 a}\right)^{2}+\frac{\beta q}{a}-(n+\beta)}
\end{aligned}
$$

The equilibrium is stable if the following inequality holds,

$$
\frac{a+(m(1-q)+\beta)}{2 a}-\sqrt{\left(\frac{a-(m(1-q)+\beta)}{2 a}\right)^{2}+\frac{\beta q}{a}}<\frac{n+\beta}{b}
$$

The left side of the above inequality is a decreasing function of $q$. This inequality is equivalent to $q>q_{c}$, where the critical proportion of artificial inoculation is given as

$$
q_{c}=\frac{b(m+\beta)-(m+\beta)(n+\beta)-a\left(1-\frac{n+\beta}{b}\right)(n+\beta)}{b(m+\beta)-m(n+\beta)}=\frac{\left(R_{z}-1\right)\left(1-R_{y} / R_{z}\right)}{R_{z}-m /(m+\beta)}
$$

For the second equilibrium, where the severe virus persists,

$$
y^{*}=\frac{q(n+\beta)(b-n)}{b(m+\beta)-a(n+\beta)+q b(n-m)} \text { and } z^{*}=1-y^{*}-\frac{n+\beta}{b}
$$

the eigenvalues of its community matrix are determined by

$$
\begin{gathered}
|A-\lambda I|=\left|\begin{array}{cc}
\frac{a(n+\beta)}{b}-a y^{*}-(m+\beta)+m q-\lambda & -a y^{*}+n q \\
-b z^{*} & -b z^{*}-\lambda
\end{array}\right|= \\
\left|\begin{array}{cc}
2 \frac{a(n+\beta)}{b}-a+a z^{*}-(m+\beta)+m q-\lambda & (m+\beta)-m q+n q-\frac{a(n+\beta)}{b}+\lambda \\
-b z^{*} & -\lambda
\end{array}\right|= \\
\lambda^{2}+C_{1} \lambda+C_{2}
\end{gathered}
$$

where

$$
\begin{aligned}
& C_{1}=a\left[\frac{m+\beta}{a}-2 \frac{n+\beta}{b}+1-\frac{m q}{a}+\frac{b-a}{a} z^{*}\right] \\
& C_{2}=q[m(n+\beta)-b(m+\beta)]+b(m+\beta)-a(n+\beta)-(n+\beta)(m+\beta)+\frac{a(n+\beta)^{2}}{b}
\end{aligned}
$$

According to the Ruth-Hurwitz theorem (48) the two eigenvalues are negative if and only if $C_{1}>0$ and $C_{2}>0$. These are satisfied if the following inequality holds,

$$
\frac{m(1-q)+\beta+a}{2 a}-\sqrt{\left(\frac{a-(m(1-q)+\beta)}{2 a}\right)^{2}+\frac{q \beta}{a}}>\frac{n+\beta}{b}
$$

Because the maximum of the left side is $\min \{1,(m+\beta) / a\}$, we then have $b /(n+\beta)>1$. It is easy to check that

$$
\frac{m+\beta}{a} \geq \frac{m(1-q)+\beta+a}{2 a}-\sqrt{\left(\frac{a-[m(1-q)+\beta]}{2 a}\right)^{2}+\frac{q \beta}{a}}
$$

which leads to $(m+\beta) / a>(n+\beta) / b$. This means that, with managed cross protection, the requirements $R_{z}>1$ and $R_{z}>R_{y}$ are necessary, but not sufficient for the virulent virus strain to persist.

\section{APPENDIX B}

Effect of season on an epidemic of a single disease agent. Considering the infection of a crop-host by a single virus, equations $4 \mathrm{a}$ can be reduced to

$$
\frac{d z}{d t}=b(1-z) z
$$

which can be solved by integrating

$$
z=\frac{z_{0} \exp (b t)}{1+z_{0}(\exp (b t)-1)}
$$

Here $z_{0}$ is the initial incidence. The incidence will progress to a level $z_{1}=z_{0} \exp (b T) /\left\{1+z_{1}[\exp (b T)-1]\right\}$ at the end of a growing season of duration $T$, and in the next growing season will start from the new initial incidence $\varepsilon z_{1}$, and end with the incidence

$$
z_{2}=\frac{\varepsilon z_{1} \exp (b T)}{1+\varepsilon z_{1}(\exp (b T)-1)} \equiv g\left(z_{1}\right)
$$

The epidemic at the end of growing seasons will progress as $z_{1}$, $z_{2}, \ldots$ and so on. We now examine the dynamical behavior of this epidemic series.

Notice that

$$
\frac{d g\left(z_{1}\right)}{d z_{1}}=\frac{\varepsilon \exp (b T)}{\left\{1+\varepsilon z_{1}[\exp (b T)-1]\right\}^{2}}>0
$$

which shows that $z_{2}=g\left(z_{1}\right)$ is an increasing function for any $z_{1}>$ 0 . Thus, no chaotic behavior is expected for the epidemic series (64). Let

$$
G\left(z_{1}\right) \equiv g\left(z_{1}\right)-z_{1}=\frac{\varepsilon z_{1} \exp (b T)-z_{1}-\varepsilon z_{1}^{2}[\exp (b T)-1]}{1+\varepsilon z_{1}[\exp (b T)-1]}
$$

That is, $G\left(z_{1}\right)$ is the difference between disease incidence at the end of the present growing season and that at the end of a previous growing season. If disease incidence increases year by year, then $G>0$; If disease incidence decreases, then $G<0$. If disease incidence is constant, then $G=0$. The virus persistence criterion can be obtained by analyzing the dynamical characteristics of function $G\left(z_{1}\right)$. 
Consider two special points $z_{1}=0^{+}, 1$ where $z_{1}=1$ is the possible maximum equilibrium. Here $0^{+}$represents an infinitesimal positive value. If $\exp (b T)>1$, then $G\left(0^{+}\right)>0$ and $G(1)<0$. According to the intermediate value theorem (4) and the monotonic increase of $z_{2}=g\left(z_{1}\right)$, there exists one and only one value $z^{*} \in(0,1)$ satisfying $G\left(z^{*}\right)=0$ (i.e., $z_{2}=z_{1}=z^{*}$ ). The value of this fixed point, independent of the initial incidence, was determined by the equation $\mathrm{G}\left(z^{*}\right)=0$, i.e.,

$$
1=\varepsilon \frac{\exp (b T)}{1+\varepsilon z^{*}[\exp (b T)-1]}
$$

which illustrates the exact cancellation between the seasonal reduction in incidence and disease progress during the growing season. The fixed point can be explicitly expressed as

$$
z^{*}=\frac{\varepsilon \exp (b T)-1}{\varepsilon[\exp (b T)-1]}
$$

It is obvious from the above equation that the maximum $z^{*}=1$ occurs when $\varepsilon=1$ (continuous crop-host availability), and $z^{*}<1$ for any $\varepsilon<1$. There are two fixed points (equilibria): the origin and $z^{*}$. The former is unstable due to

$$
\left.\frac{d g\left(z_{1}\right)}{d z_{1}}\right|_{z_{1}=0}>1
$$

and the latter is stable due to

$$
\left.\frac{d g\left(z_{1}\right)}{d z_{1}}\right|_{z_{1}=z^{*}}<1
$$

Therefore, if $\varepsilon \exp (b T)>1$ is satisfied, the disease can persist. If $\varepsilon \exp (b T)<1$, then $G\left(z_{1}\right)<0$ for any $z_{1} \in(0,1)$. Thus, there exists only one fixed point (the origin) and it is stable because

$$
\left.\frac{d g\left(z_{1}\right)}{d z_{1}}\right|_{z_{1}=0}<1
$$

Illustrations of these two cases are shown in Figure 6A and B. Definitions of symbols used in the models are given in Table 6.

\section{ACKNOWLEDGMENTS}

We thank M. Thresh for his constructive criticism on an earlier version of this manuscript. X.-S. Zhang was supported by a Ph.D. studentship at the University of Greenwich.

\section{LITERATURE CITED}

1. Aapola, A. I. E., and Rochow, W. F. 1971. Relationships among three isolates of barley yellow dwarf virus. Virology 46:127-141.

2. Anderson, R. M., and May, R. M. 1982. Directly transmitted infectious diseases: Control by vaccination. Science 215:1053-1060.

3. Anderson, R. M., and May, R. M. 1996. The population biology of the interaction between HIV-1 and HIV-2: Coexistence or competitive exclusion? AIDS 10:1663-1673.

4. Bajpai, A. C., Mustoe, L. P., and Walker, D. 1989. Engineering Mathematics. 2nd ed. John Wiley \& Sons, New York.

5. Bar-Joseph, M., Garnsey, S. M., and Gonsalves, D. 1979. The closteroviruses: A distinct group of elongated plant viruses. Adv. Virus Res. 25:93-168

6. Bar-Joseph, M., and Loebenstein, G. 1973. Effects of strain, source plant, and temperature on the transmissibility of citrus tristeza virus by the melon aphid. Phytopathology 63:716-720.

7. Bar-Joseph, M., Marcus, R., and Lee, R. F. 1989. The continuous challenge of citrus tristeza virus control. Annu. Rev. Phytopathol. 27:291316.

8. Bar-Joseph, M., Roistacher, C. N., and Garnsey, S. M. 1983. The epidemiology and control of citrus tristeza disease. Pages 61-72 in: Plant Virus Epidemiology: The Spread and Control of Insect Borne Viruses. R. T. Plumb and J. M. Thresh, eds. Blackwell Scientific Publications, Oxford.

9. Bennett, C. W., and Costa, A. S. 1949. Tristeza disease of citrus. J. Agric. Res. 78:207-237.
10. Branch, A. D., Benenfeld, B. J., Frank, E. R., Shaw, J. F., Varban, M. L., Willis, K. K., Rosen, D. L., and Robertson, H. D. 1988. Interference between coinoculated viroids. Virology 163:538-546.

11. Bremermann, H. J., and Thieme, H. R. 1989. A competitive exclusion principle for pathogen virulence. J. Math. Biol. 27:179-190.

12. Bridges, G. D., and Youtsey, C. O. 1972. Natural tristeza infection of citrus species, relatives and hybrids at one Florida location from 19611971. Proc. Fla. State Hortic. Soc. 85:44-47.

13. Broadbent, L. 1976. Epidemiology and control of tomato mosaic virus. Annu. Rev. Phytopathol. 14:75-96.

14. Burrows, P. M. 1995. Dynamics of unilateral and bilateral protection. Page 50 in: Epidemiological Aspects of Plant Virus Control. B. Raccah, ed. Phytopathological Society of Israel, Bet Dagan.

15. Campbell, C. L., and Madden, L. V. 1990. Introduction to Plant Disease Epidemiology. John Wiley \& Sons, New York.

16. Chan, M. S., and Jeger, M. J. 1994. An analytical model of plant virus disease dynamics with roguing and replanting. J. Appl. Ecol. 31:413427.

17. Costa, A. S., and Muller, G. W. 1980. Tristeza control by cross protection: A US-Brazil cooperative success. Plant Dis. 64:538-541.

18. Fletcher, J. T. 1978. The use of avirulent strains to protect plants against the effects of virulent strains. Ann. Appl. Biol. 89:110-114.

19. Fulton, R. W. 1986. Practices and precautions in the use of cross protection for plant virus disease control. Annu. Rev. Phytopathol. 24:67-81.

20. Gildow, F. E., and Rochow, W. F. 1980. Transmission interference between two isolates of barley yellow dwarf virus in Macrosiphum avenae. Phytopathology 70:122-126.

21. Grant, T. J., and Costa, A. S. 1951. A mild strain of the tristeza virus of citrus. Phytopathology 41:114-122.

22. Gubbins, S., and Gilligan, C. A. 1997. A test of heterogeneous mixing as a mechanism for ecological persistence in disturbed environments. Proc. R. Soc. Lond. B 264:227-232.

23. Gubbins, S., and Gilligan, C. A. 1997. Biological control in a disturbed environment. Philos. Trans. R. Soc. Lond. B 352:1935-1949.

24. Harrison, B. D. 1958. Ability of single aphids to transmit both avirulent and virulent strains of potato leaf roll virus. Virology 6:278-286.

25. Hermoso de Mendoza, A., Ballester-Olmos, J. F., and Pina, J. A. 1988. Comparative aphid transmission of a common citrus tristeza virus isolate and a seedling yellows isolate recently introduced into Spain. Pages 6870 in: Proc. 10th Conf. Int. Organ. Citrus Virol. L. W. Timmer, S. M. Garnsey, and L. Navarro, eds. IOCV, Riverside, CA.

26. Hewings, A. D., and Eastman, C. E. 1995. Epidemiology of barley yellow dwarf in North America. Pages 75-106 in: Barley Yellow Dwarf: 40 Years of Progress. C. J. D'Arcy and P. A. Burnett, eds. The American Phytopathological Society, St. Paul, MN.

27. Holt, J., and Chancellor, T. C. B. 1997. A model of plant disease epidemics in asynchronously-planted cropping systems. Plant Pathol. 46: 490-501.

28. Holt, J., and Chancellor, T. C. B. 1999. Modeling the spatio-temporal deployment of resistant varieties to reduce the incidence of rice tungro disease in a dynamic cropping system. Plant Pathol. 48:453-461.

29. Holt, J., Jeger, M. J., Thresh, J. M., and Otim-Nape, G. W. 1997. An epidemiological model incorporating vector population dynamics applied to African cassava mosaic virus disease. J. Appl. Ecol. 34:793-806.

30. Irwin, M. E., and Thresh, J. M. 1990. Epidemiology of barley yellow dwarf: A study of ecological complexity. Annu. Rev. Phytopathol. 28:393-424.

31. Jedlinski, H., and Brown, C. M. 1965. Cross protection and mutual exclusion by three strains of barley yellow dwarf virus in Avenae sativa L. Virology 26:613-621.

32. Jeger, M. J., Van Den Bosch, F., Madden, L. V., and Holt, J. 1998. A model for analysing plant-virus transmission characteristics and epidemic development. IMA J. Math. Appl. Med. Biol. 15:1-18.

33. Kakehashi, M., 1996. Populations and infectious diseases: Dynamics and evolution. Res. Popul. Ecol. 38:203-210.

34. Lecoq, H., Lemaire, J. M., Bourdin, D., and Wipf-Scheibel, C. 1991. Control of zucchini yellow mosaic virus in squash by cross protection. Plant Dis. 75:208-211.

35. Lee, R. F., Brlansky, R. H., Garnsey, S., and Yokomi, R. K. 1987. Traits of citrus tristeza virus important for mild strain cross protection of citrus: The Florida approach. Phytophylactica 19:215-218.

36. Levin, S., and Pimentel, D. 1981. Selection of intermediate rates of increase in parasite-host systems. Am. Nat. 117:308-315.

37. Lipsitch, M., and Nowak, M. A. 1995. The evolution of virulence in sexually transmitted HIV/AIDS. J. Theor. Biol. 174:427-440.

38. Madden, L. V., Pirone, T. P., and Raccah, B. 1987. Temporal analysis of two viruses increasing in the same tobacco fields. Phytopathology 77:974-980.

39. Mayo, M. A., and D'Arcy, C. J. 1999. Family Luteoviridae: A reclassi- 
fication of Luteoviruses. Pages 15-22 in: The Luteoviridae. H. G. Smith and H. Barker, eds. CABI Publishing, Wallingford, U.K.

40. Mayo, M. A., and Pringle, C. R. 1998. Virus taxonomy-1997. J. Gen. Virol. 79:649-657.

41. McKinney, H. H. 1929. Mosaic diseases in the Canary Islands, West Africa and Gibraltar. J. Agric. Res. 39:557-578.

42. Miller, N. R., Bergstrom, G. C., and Gray, S. M. 1991. Identity, prevalence, and distribution of viral diseases in winter wheat in New York in 1988 and 1989. Plant Dis. 75:1105-1108.

43. Miller, W. A., Koev, G., and Mohan, B. R. 1997. Are there risks associated with transgenic resistance to luteoviruses? Plant Dis. 81:700710.

44. Miller, W. A., and Rasochova, L. 1997. Barley yellow dwarf viruses. Annu. Rev. Phytopathol. 35:167-190.

45. Muller, G. W., and Costa, A. S. 1977. Tristeza control in Brazil by preimmunization with mild strains. Proc. Int. Soc. Citric. 3:868-872.

46. Murphy, P. A. 1938. A discussion on new aspects of virus disease. Proc. R. Soc. Lond. B 125:307-308.

47. Nowak, M. A., and May, R. M. 1994. Superinfection and the evolution of parasite virulence. Proc. R. Soc. Lond. B 255:81-89.

48. Pielou, E. C. 1977. Mathematical Ecology. John Wiley \& Sons, New York.

49. Plumb, R. T. 1983. Barley yellow dwarf virus—a global problem. Pages 185-198 in: Plant Virus Epidemiology. R. T. Plumb and J. M. Thresh, eds. London Blackwell Science, London.

50. Plumb, R. T. 1995. Epidemiology barley yellow dwarf in Europe. Pages 107-127 in: Barley Yellow Dwarf: 40 Years of Progress. C. J. D'Arcy and P. A. Burnett, eds. The American Phytopathological Society, St. Paul, MN.

51. Posnette, A. F., and Todd, J. M. 1955. Virus disease of cacao in West Africa. IX. Strain variant and interference in virus 1A. Ann. Appl. Biol. 43:433-453.

52. Power, A. G. 1992. Patterns of virulence and benevolence in insectborne pathogens of plants. Crit. Rev. Plant Sci. 11:351-372.

53. Power, A. G. 1996. Competition between viruses in a complex plantpathogen system. Ecology 77:1004-1010.

54. Raccah, B., Roistacher, C. N., and Barbagallo, S. 1989. Semi-persistent transmission of viruses by vectors with special emphasis on citrus tristeza virus. Adv. Dis. Vector Res. 6:301-340.
55. Rocha-Pena, M. A., Lee, R. F., Lastra, R., Niblett, C. L., Ochoa-Corona, F. M., Garnsey, S. M., and Yokomi, R. K. 1995. Citrus tristeza virus and its aphid vector Toxoptera citricida. Plant Dis. 79:437-445.

56. Rochow, W. F. 1969. Biological properties of four isolates of barley yellow dwarf virus. Phytopathology 59:1580-1589.

57. Rochow, W. F. 1970. Barley yellow dwarf virus: Phenotypic mixing and vector specificity. Science 167:875-878.

58. Rochow, W. F. 1979. Field variants of barley yellow dwarf virus: Detection and fluctuation during twenty years. Phytopathology 69:655-660.

59. Rochow, W. F., and Muller, I. 1974. Mixed infections of barley yellow dwarf virus isolates in winter grains. Plant Dis. Rep. 58:472-475.

60. Rochow, W. F., and Muller, I. 1976. Gradual change in predominating isolates of barley yellow dwarf virus in New York. Plant Dis. Rep. 60:387-390.

61. Rochow, W. F., Muller, I., and Gildow, F. E. 1983. Interference between two luteoviruses in an aphid: Lack of reciprocal competition. Phytopathology 73:919-922.

62. Roistacher, C. N., and Bar-Joseph, M. 1984. Transmission of tristeza and seedling yellow tristeza virus by Aphis gossypii from sweet orange, grapefruit and lemon to Mexican lime, grapefruit and lemon. Pages 9-18 in: Proc. 9th Conf. Int. Organ. Citrus Virol. S. M. Garnsey, L. W. Timmer, and J. A. Dodds, eds. IOCV, Riverside, CA.

63. Salaman, R. N. 1933. Protecting inoculation against a plant virus. Nature 131:468.

64. Shaw, M. W. 1994. Seasonally induced chaotic dynamics and their implication in models of plant disease. Plant Pathol. 43:790-801.

65. Smith, H. C. 1963. Interaction between isolates of barley yellow dwarf virus. N.Z. J. Agric. Res. 6:343-353.

66. Vanderplank, J. E. 1963. Plant Diseases: Epidemics and Control. Academic Press, New York.

67. Yeh, S.-D., Gonsalves, D., Wong, H.-L., Namba, R., and Chiu, R.-J. 1988. Control of papaya ringspot virus by cross protection. Plant Dis. 72:375-380.

68. Zhang, X.-S., Holt, J., and Colvin, J. 2000. A general model of plantvirus disease infection incorporating vector aggregation. Plant Pathol. 49:435-444

69. Zhang, X.-S., Holt, J., and Colvin, J. 2000. Mathematical models of host plant infection by helper-dependent virus complexes: Why are helper viruses always avirulent? Phytopathology 90:85-93. 